\title{
Villes et paysages dans le monde hispanique
}

Espaces et représentations

\section{Christine Delfour et Joséphine Marie}

\section{(2) OpenEdition}

Journals

Édition électronique

URL : http://journals.openedition.org/agedor/1345

DOI : 10.4000 /agedor.1345

ISSN : 2104-3353

Éditeur

Laboratoire LISAA

Référence électronique

Christine Delfour et Joséphine Marie, "Villes et paysages dans le monde hispanique », L'Âge d'or [En ligne], 10 | 2017, mis en ligne le 08 janvier 2019, consulté le 23 septembre 2020. URL : http://

journals.openedition.org/agedor/1345; DOI : https://doi.org/10.4000/agedor.1345

Ce document a été généré automatiquement le 23 septembre 2020.

L'Âge d'or. Images dans le monde ibérique et ibéricoaméricain 


\title{
Villes et paysages dans le monde hispanique
}

\author{
Espaces et représentations
}

Christine Delfour et Joséphine Marie

1 S'interroger sur les espaces et les représentations de la ville et des paysages dans le monde hispanique en entrecroisant, comme toujours, nos disciplines (littérature, poésie, civilisation, cinéma, peinture, etc.) tel est l'objectif des deux dossiers présentés dans ce numéro 10 de la revue L'Âge d'Or par l'équipe interne Écritures des Mondes hispaniques (EMHIS) avec la participation de chercheurs français et étrangers (principalement espagnols et latino-américains).

2 La ville est d'abord l'espace complexe d'une multiplicité : multiplicité des fonctions, des paysages et multiplicité des hommes et des femmes qui la composent. C'est un espace d'attractivités tous azimuts où se croisent toutes sortes de cultures, de catégories sociales différentes. C'est un carrefour d'espace-temps, un foisonnement non planifié, ce qui en fait sa richesse et d'où se construit une civilisation constamment enrichie par le rapport de l'autre. C'est également un espace « du commun ", c'est cette façon qu'ont les citoyens d'en partager l'histoire ainsi qu'un bout du destin commun. C'est, enfin, un espace public en éternelle construction, déconstruction et reconstruction qui doit correspondre au mieux au temps de vie du vécu de chacun et des collectifs qui l'habitent. De multiples frontières traversent ces espaces de la ville créant autant de nouvelles formes de territorialités, d'identités, d'imaginaires et de représentations.

En Amérique latine, en ce début de xxI siècle, ce sont 500 millions d'habitants vivant dans les villes sur une population totale de plus de 620 millions qui en font un espace essentiellement urbain. En Espagne, ce sont les villes qui ont, tout au long d'une histoire complexe et parfois chaotique, été le milieu d'innovations, le centre de la modernisation et de modernité. Il nous est apparu donc pertinent de consacrer une réflexion commune à ces deux espaces Espagne-Amérique latine autour de la ville.

Prolongement des réflexions menées sur la ville, le second dossier interroge plus largement certains processus de constructions et déconstructions des paysages, à la croisée des disciplines, des aires géographiques, des époques mais aussi des « objets». 
Envisagé tant dans ses pratiques que dans ses représentations, le paysage, à la fois matérialité et perception, contribue spécifiquement à l'inscription d'une plastique et à la création de nouvelles identités et imaginaires en ce qu'il est véritable point d'articulation entre l'expérience sensible d'un espace, le voir et le dire. Inévitable fruit d'une construction et substitut potentiel de la parole, en particulier face à l'indicible, il émerge comme lieu de création de nouveaux savoirs(êtres), de défiance ou de permanence des discours établis, et comme endroit de la mise en «place» de diverses idéologies.

Les itinéraires au sein des mondes hispaniques ici envisagés, à travers les nouveaux territoires de l'analyse des images paysagères, au fil des récits et reconfigurations de celles-ci, ou encore depuis la variété des transformations poétiques, mènent à un constat : les moments paysagers surgissent d'abord en temps de crise et sont toujours, pleinement ou en creux, porteurs d'une histoire passée ou présente (nationalisme espagnol face aux identités multiculturelles et au nationalisme marocain, déconstruction de la mémoire franquiste, crise du sujet face à sa finitude, Histoire officielle et mémoire coloniale à Cuba, réalités et illusions baroques, paysages et réalités virtuelles de notre contemporanéité, etc.).

Dans ses visions et formes multiples, du Siècle d'or à nos jours, de Ceuta à Cuba, en passant par les Canaries, la Castille ou encore l'Andalousie, il s'agira donc de comprendre comment le paysage se donne à voir, au-delà de l'enjeu purement descriptif et de ses fonctions mimétiques, comme un délicat point de jonction où se nichent tout autant la parcelle que la totalité, la verticalité que l'horizontalité, l'unicité que la pluralité des espace-temps, la détermination que l'indétermination, l'éclatement que la fusion, l'expérience individuelle que l'expérience collective ou universelle. Il sera question d'entendre, depuis ses composantes perceptibles comme ses vides et ses lacunes, comment il témoigne et se fait lieu de la crise des savoirs et des "voirs». Comment il est à la fois révélation et révélateur, nous invitant peut-être à nous éloigner de l'intériorisation de certains modèles interprétatifs dominants et de certains conditionnements auxquels nous sommes habitués, élargissant alors immanquablement nos horizons.

\section{AUTEURS}

CHRISTINE DELFOUR

LISAA EA 4210

JOSÉPHINE MARIE

LISAA EA 4210 